\title{
Discussion on the Mixed Teaching Reform of College Service and Management Courses in the Post-epidemic Era
}

\author{
Xiaoliang Chen ${ }^{1, *}$
}

\begin{abstract}
${ }^{1}$ Tourism and Urban Management College, Tourist Development Research Center, Jiangxi University of Finance and Economics, Nanchang City, Jiangxi, 330032, China.

*Corresponding author. Email: jxchenxiaoliang@163.com
\end{abstract}

\begin{abstract}
The purpose of the study is to discuss the new situation of mixed teaching of service management courses in the Post-epidemic era, in response to these new realities, in this study, the evaluation mechanism is deeply considered, the ideological and political education is theoretically discussed, and the results of the questionnaire are sorted out, interpreted and analyzed to explore the characteristics of the mixed teaching of service management courses in colleges and universities. It played a positive and effective educational function in the COVID-19 era. It changed the educational concept in the Post-epidemic era and achieved certain teaching results. This has certain theoretical and practical significance for the teaching reform of higher education.
\end{abstract}

Keywords: Service management curriculum; Mixed teaching; Teaching reform; Post-epidemic era

\section{INTRODUCTION}

"Blended Learning" is also known as "mixed teaching" and "online and offline + teaching". The year 2020 is a key year for China's teaching and education reform. This year, COVID-19 ravaged the world, and the education industry was also impacted. "Although classes are not suspended." Chinese universities have generally adopted the mode of online teaching to make up for the lack of offline teaching. Since then, online and offline teaching has been integrated, creating a new way of combining the theory and practice of teaching and teaching reform. The year has become the iconic year in which Mixed teaching was popularized.

Service management courses in universities are generally in the form of general courses. It is a humanities and social science course that spreads ancient and modern Chinese and foreign service management cultural knowledge, as well as modern service management norms.

In terms of teaching content, teachers attach not only importance to the explanation of service management culture theoretical knowledge, but also to the practical operation of modern service management knowledge. In the teaching preparation work, teachers abide by the school's teaching rules, use learning to sign in, and upload the necessary syllabus, teaching schedule and relevant teaching resources on the online teaching platform. Teachers will fully combine the daily classroom teaching, network teaching and the corresponding second classroom. In the specific teaching practice of the course, teachers use multimedia teaching facilities to demonstrate the text, videos, pictures of the courseware, and combined with situational simulation training, so as to achieve the full use of a variety of teaching means, to achieve the multidimensional integrated teaching effect. Through the study of this course, students can master the basic theoretical knowledge of Chinese and foreign service management, become qualified modern man, and lay a foundation for entering society and engaging in relevant work positions in the future. Therefore, how to carry out a new thinking on its mixed teaching reform in the post-epidemic era has become an urgent problem faced by such courses.

\section{THE CONCEPT AND ROLE OF ONLINE AND OFFLINE MIXED TEACHING}

In 2000, Cooney proposed the Mixed Teaching Model (Blended Learning) [1], the first time ever proposed by academia. This new theory of teaching mode was valued at home and abroad and began to develop. What is more popular in foreign academia is Garrison's teaching viewpoint. He puts forward that mixed teaching is a model that integrates traditional classroom teaching and online teaching. [2] He Kekang (2004) gives a new meaning to blended learning, and proposes to combine the advantages of traditional teaching with digital and network learning, so as to give full play to the interaction between teachers and students. [3] "The Guiding Opinions of the Ministry of Education on Deepening the Reform of Education and Teaching" issued in 2016 put forward the requirements of promoting the inter-campus online and offline Mixed teaching mode, which has certain guiding significance for mixed teaching and promotes the teaching theory circle to pay further attention to the teaching mode. In 2019,"the 
Notice of the General Office of the Ministry of Education on the Recognition of National First-class Undergraduate Courses in Offline, Online and offline Mixed and Social Practice in 2019" has effectively promoted the progress of mixed teaching theory, so that the mixed teaching reform has entered a new stage of development.

With the popularity of the Internet, the education industry caters to the opportunity of this high-tech development and vigorously promotes intellectual products and technological innovation. The operation mode of "Internet + Higher Education" has gradually developed and has special educational and teaching functions.

In the traditional offline teaching classroom, educators perceive a single and boring educational resource transformation mode. In a simple online teaching classroom, educators may be unable to accept educational resources effectively due to lack of teacher supervision or limited to limited online resources, and educators cannot effectively organize reasonable teaching space, resulting to the poor transmission of teaching resources and inadequate education.

Under this Mixed online and offline teaching mode, teaching managers can use high-tech means, integrate educational resources, provide more advanced and efficient teaching training for trainees, ensuring more efficient teaching quality; and educators can also escape from the traditional education and teaching mode, play their own initiative and enthusiasm, accept more standardized and flexible education mode, thus improving the resource transformation of classroom limited time and space.

At present, the academic research on mixed teaching has gone through several stages from theoretical research, practical exploration to diversified development [4].Colleges at home and universities are exploring scientific mixed online and offline teaching mode, and exploring the multi-level innovation and improvement of their teaching methods, teaching content, teaching purpose, teaching focus and difficulties, teaching evaluation and teaching feedback, so as they can adapt to the new teaching environment after COVID-19.

\section{CHARACTERISTICS OF MIXED TEACHING OF SERVICE MANAGEMENT COURSES}

Mixed teaching of online and offline service management has its historical development inevitability. The use of mixed online and offline teaching in service management courses is the development trend of The Times and the demand of the real higher education reform.

First, traditional service management teaching methods need innovation. Relying solely on the indoctrination of theoretical knowledge in the classroom has long been unable to meet the needs of modern higher education.

Second, combines with the after-curricular teaching practice mode of travel agency practical tutors, which has been implemented in some universities, has achieved certain classroom teaching effect and stimulated the enthusiasm of students to participate in internship practice. Fully combining theory and practice can let students apply the classroom theoretical knowledge in practical social work, confirm the theoretical knowledge, and feedback their practical effect in the theoretical structure and reconstruction.

Third, based on the analysis of the characteristics of the development of the Post-epidemic era, online and offline service management teaching is a fully developed teaching mode transformation and innovation. It is also the full use and embodiment of high technology in the Internet era.

Fourth, from the perspective of the construction and interaction of teaching platform, educators rely on Chaoxing, MOOC, DingTalk, Tencent classroom and WeChat group chat platform and their abundant resources, to build a blended learning way integrating online and offline. Students rely on the online teaching platform to conduct "online" learning, and conduct online communication between educators and students. Educators can also establish QQ group and WeChat group to conduct convenient question-answering and interaction between educators and students after class.

\section{THE EFFECT AND EVALUATION MECHANISM OF THE MIXED TEACHING OF SERVICE MANAGEMENT COURSES}

From the analysis of educational concept, the teaching of service courses can improve the inner quality of students and improve their comprehensive ability, especially in the teaching and training links, which has practical significance for students to master their practical operation skills and improve their practical ability. The Mixed online and offline teaching method is highly in line with the national education concept and provides new ways for the country to train service-oriented talents.

\subsection{The Effect of Mixed Teaching in Service Management Courses}

Compared with the traditional teaching mode, the blended learning effect of service management courses is quite significant.

From the perspective of teachers' work, teachers can integrate online and offline teaching resources, such as MOOC can reference network teaching resources, combined with the characteristics of service management curriculum itself, make the best use of service management course teaching conditions, multi-dimensional teaching, under the vertical and horizontal teaching horizon, depth mining and broaden the depth and breadth of teaching, From the perspective of students' learning, it can improve students' autonomous learning ability, cultivate their own innovation ability and problem-solving ability, guide students to explore, reflect and innovate, and effectively 
strengthen the cultivation of students' comprehensive ability. So as to improve the quality of all graduates.

\subsection{Assessment and Evaluation Mechanism of the Mixed Teaching of Service Management Courses}

Mixed teaching of service management courses should establish a multi-dimensional and three-dimensional evaluation system to reflect the results and objectives of mixed teaching. The assessment of students is divided into online and offline assessment systems. Online assessment is mainly the usual results, it mainly consists of attendance, usual homework, online test and online discussion; offline assessment is mainly through the final exam, which can be an open or closed-volume exam. The results of these two parts are 50\% respectively. Online assessment mainly relies on the network teaching platform, with specific theoretical knowledge as the basis of assessment, so as to consolidate and deepen students 'understanding depth and breadth of students' classroom knowledge, so as to obtain the daily knowledge of mixed teaching. The offline assessment mainly relies on the teaching classroom, which takes the whole semester knowledge as the assessment content in the form of thematic or summative testing, so as to test whether the students grasp the teaching content of this course, and to evaluate whether the teaching objectives set by teachers are achieved.

The assessment of teachers' teaching achievements is also the judgment basis to verify whether the actual teaching effect has reached the established teaching objectives, which can be detected and evaluated through papers, topics and Teaching Achievements Summary. Service management courses generally pay more attention to the improvement of practical operation and training, so the actual ability and employability of students after graduation also reflect the test of teachers' teaching results.

\section{THE FEEDBACK OF THE NETWORK QUESTIONNAIRE RESULTS OF THE MIXED TEACHING OF SERVICE MANAGEMENT COURSES}

This paper conducted a network questionnaire survey on the mixed teaching of service management courses, and the results are as follows.

\subsection{The Positive Aspects Shown by the Questionnaire Results.}

First, most students believe that the mixed teaching methods of service management courses can "let students master more theory and knowledge";

Second, most students believe that the mixed teaching of service management courses "adopts multimedia teaching, with classroom interaction", and adopts the online and offline teaching mode, which is acceptable;

Third, most students believe that the teaching focus and difficulties of the mixed teaching of service management courses can be more finely solved;

Fourth, most of the students think that the mixed teaching homework of service management courses can test the effect of classroom teaching better, and can feed back the shortcomings of students in learning.

Fifth, most of the students think that online discussion of Mixed Teaching of service management courses is an extension and supplement of offline discussion, which can promote the activity of the classroom.

Sixth, most of the students think that the network teaching platform of mixed teaching of service management courses can meet the current teaching activities, so as to achieve the expected teaching purpose.

\subsection{The Questionnaire Results Show That There Are Some Problems in the Specific Application of the Mixed Teaching of Service Management Courses.}

First, from the perspective of the national level of education and teaching, the Ministry of education, in response to the sudden outbreak of the new crown disease, proposes a policy of "ceasing teaching, stopping teaching and learning without stopping." In early 2020, novel coronavirus pneumonia affected more than 190 countries in the world to close schools, and more than 1 billion 500 million students received online teaching. Blended teaching will become the mainstream teaching mode in the Post-epidemic era. Therefore, at the national level, there should be new exploration and innovation in the formulation of education strategy, so as to meet the changes of the new education environment. This is also the response of the educational environment change to the national education development strategy in the Postepidemic era.

Second, from the analysis of the software and hardware facilities of colleges and universities, some teaching software and hardware facilities need to be updated. Therefore, in the post-epidemic era, some institutions are urged to improve their software and hardware and invest more funds in the expansion of teaching resources.

Third, from the perspective of teachers' conditions, college teachers have been facing the challenge and innovation of new teaching mode innovation. Therefore, it puts forward new challenges and opportunities for teachers' Continuing Education and learning. Colleges and universities continue to provide teachers with a platform for continuing education, prompting teachers to respond to the new educational environment and innovative thinking of teaching reform.

Fourth, from the perspective of students, some students are more inclined to offline learning and lack the enthusiasm of online learning under the strict teaching supervision and management. They lack binding teaching management, so 
single online teaching can not produce effective teaching effect, and can not get good teaching feedback.

Fifth, in the construction of online teaching platform, students need to meet the learning needs of one semester. The online course platforms used mainly include Chaoxing, Tencent conference, Tencent classroom, MOOC of Chinese University and Quiz-tree. Redundant platform will bring students additional psychological and behavioral burden, and even generate aversion. Therefore, different schools need to choose their own network teaching platform to meet the needs of the educators and educatees because of the differences of their own conditions.

Sixth, from the perspective of teacher-student interaction, Lewin, a famous scholar, divides the types of teacherstudent interaction into autocratic type, democratic type and laissez faire type (Lewin, 1939). The reform measures of blended teaching really need to be analyzed from the current situation after the epidemic situation. In order to complete the teaching link and make teaching bright, in the process of online continuous communication with students of various majors, very few students are discouraged, delayed, perfunctory and so on. Therefore, teachers have various ways to negotiate, motivate, supervise and urge students. Sometimes, it is true that there is a state of "forcing a donkey to dance". In fact, teachers can not supervise students' learning, and students may be tired of learning, lazy, even disgusted and rebellious. In addition, after the epidemic, we need to further improve our communication ability, psychological self-regulation ability and pressure resistance ability. Therefore, effective communication with the new generation of students needs to continue to explore better ways.

Seventh, discussion on the integration of ideological and political elements in the mixed teaching of service management courses. The National Conference on Ideological and political work in Colleges and universities held in December 2016 stressed that all kinds of courses and ideological and political theory courses should go hand in hand to form a synergistic effect. In June 2020, the Ministry of Education issued "the guiding outline for the ideological and political construction of higher education curriculum", which highlights the necessity, importance and urgency of building "curriculum ideological and political" and realizing "curriculum ideological and political" and "Ideological and Political Curriculum" going together.

The core goal of higher education is to teach and educate people. The fundamental task of higher education is to establish morality and cultivate people. In the postepidemic era, how to cultivate all-round development of qualified students who can adapt to the innovation of the times, which puts forward a more long-term strategic concept for the mixed teaching of service management courses. This is embodied in the following aspects: the formulation of teaching plan, the design of teaching objectives, the selection of teaching emphasis and difficulty, the evaluation and feedback of teaching effect, etc. How to implement the teaching reform concept of ideological and political course, so that the implicit education function can be fully played out, and how to design the relevant teaching links, so that the ideological and political education can imperceptibly penetrate into the students learning, so as to improve the actual effectiveness of ideological and political course in teaching and educating people. Then we think about how to tap the ideological and political elements and resources of service management courses, so as to integrate them into all aspects of teaching, and make them conducive to the overall development of students' morality, wisdom, physical, aesthetics and labour education [5]. This has become one of the tasks of China's education reform.

\section{CONCLUSION}

The mixed teaching of online and offline service management courses is the embodiment of the historical law of the development of higher education in the Postepidemic era. It should not only reflect the advantages of Mixed Teaching in the Post-epidemic era, but also reflect the practical characteristics of service management courses. From the perspective of higher education management, it is necessary to formulate a strategic top-level design to deal with the new development of higher education in the Postepidemic era. It is also necessary to give full play to the ability of guidance and supervision decision-making, integrate and deeply tap the mixed teaching resources, so as to fully serve the education.

From the perspective of teachers, we should think about the design of teaching process, teaching objectives, teaching content, teaching emphasis and difficulty, teaching assessment, teaching effect evaluation and other aspects in an all-round way, so as to make full use of and integrate high-quality resources in teaching activities and further innovate teaching activities.

From the perspective of students, the mixed teaching of service management courses in the Post-epidemic period is undoubtedly a new challenge and opportunity for students' learning ability, which needs to enhance students' learning initiative and enthusiasm, and also to enhance the determination of the new generation of young students to resist the epidemic bravely and tenaciously, overcome impetuous mentality, establish service awareness, and develop their own ability to find problems Innovative ability to solve problems. This needs to be considered from the integration of ideological and political education into the teaching reform. The relevant departments should strengthen the subtle influence of the ideological and political ideas of the mixed teaching of service management courses in the new era, so as to improve the ideological quality and moral sentiment of students.

From the construction of network teaching platform to analyze, the relevant departments should make full use of and integrate the high-quality teaching resources of MOOC, Chaoxing and other platforms, make rational use of Wechat, Tencent conference, DingTalk and other network communication platform resources, and do a good job of related scientific and technological innovation and services in the software and hardware level, so that the Mixed 
teaching of higher education can be carried out smoothly [6].

\section{REFERENCES}

[1] Margaret H. Cooney, Patricia Gupton, Michael O'Laughlin, Blurring the lines of play and work to create blended classroom learning experiences," Early Childhood Education Journal, 2000(3), vol. 27, pp. 165171. DOI: https://doi.org/10.1007/bf02694230

[2] D. Randy Garrison, Heather Kanuka, "Blended learning: Uncovering its transformative potential in higher education, " The Internet and Higher Education, vol. 7, 2004(2), pp. 95-105. DOI:

https://doi.org/10.1016/j.iheduc, 2004.02.001

[3] Kekang He. The new development of educational technology theory from the perspective of blending learning. Audio visual education research, 2004 (3), pp. 1-6. DOI:10.13811/j.cnki.eer.2004.03.001

[4] Fen Peng, Huahua Jin, research topic, development context and trend analysis of Blended Teaching in Colleges and Universities -- Knowledge Mapping Research Based on cite space, Chinese university teaching, 2021 (1-2), pp. 100-105. (In Chinese)

[5]Xuqiong Meng, Zhihua Tang, the historical evolution of Ideological and political education concept since the reform and opening up, Journal of Henan Normal University, Vol . 48, 2021 (3), pp. 151-156.

DOI:10.16366/j.cnki.1000-2359.2021.03.20

[6]Chuanchao Huang, Yu-Wei Chan, Neil Yen, "Data Processing Techniques and Applications for CyberPhysical Systems, "(DPTA 2019), Advances in Intelligent Systems and Computing, 2020. (In Chinese) DOI: https://doi.org/10.1007/978-981-15-1468-5 